to establish biostratigraphic relationships 6 .

Gould and Eldredge give credit to punctuated equilibrium for an understanding of evolutionary processes above the species level, but the concept is unnecessary for species selection or sorting to work ${ }^{7}$. They misleadingly quote Williams ${ }^{8}$ who acknowledges that evolutionary processes might work above the species level but does not accept punctuated equilibrium at all. Authors they cite as supportive in fact see no particular challenge of punctuated equilibrium to evolutionary theory ${ }^{9}$. Indeed, Gould and Eldredge have devolved their claims of punctuation from an "alternative" to being "complementary". Because the complement involves placing an artificial border in a complex array, nothing of substance has been really added, even if a couple of examples now exist, and Gould and Eldredge have apparently finally admitted it.

Jeffrey Levinton

Department of Ecology and Evolution,

State University of New York,

Stony Brook, New York 11794, USA

Gould AND EldREDGE REPLy - We accept the grudging support of our oldest and severest critics in gradual increments. How lovely that Levinton now grants us "a couple of examples", which must at least make punctuated equilibrium trivial and not entirely vacuous. We stated ourselves ${ }^{1}$ that species selection and sorting do not logically require punctuated equilibrium, but it would be both contrary to the historical record (and ungenerous in the extreme) to deny that this important discussion about macroevolutionary theory was initiated and primarily nurtured in the context of 20 years' debate about punctuated equilibrium (a pattern that compels attention to species sorting as the primary mechanism of evolutionary trends).

We did not quote George Williams as a supporter of punctuated equilibrium, but neither does he share Levinton's sourness, as Williams wrote in the book we cited: "I will assume here that there is some factual validity to the pattern they [Gould and Eldredge] describe."7 We did not cite punctuated equilibrium as an alternative theory of evolution (as Levinton states), but as an alternative to the pattern of phyletic gradualism, once viewed as canonical and nearly exclusive. The title of our original 1972 article ${ }^{3}$ reads: "Punctuated equilibria: an alternative to phyletic gradualism". Alternatives are often complements, so what is Levinton's beef?

Clarke uses the venerable stratagem of "old hat" or "all been said before". But punctuated equilibrium is not the observation that evolution may occasionally move in spurts. Of course such an idea is old hat; Clarke needn't take us back to 1949 for this; why not Huxley's famous comment to Darwin in 1859: "you load yourself with an unnecessary difficulty in adopting natura non facit saltum so unreservedly."

Punctuated equilibrium is a theory that attributes this pattern of spurt and stasis neither (1) to imperfections of the fossil record in a truly gradualistic world, nor (2) to such theories of occasional anagenetic rapidity as Simpson's important

1. Gould, S. J. \& Eldredge, N. Nature 366, 223-227 (1993)

2. Jepsen, G. L., Simpson, G. G. \& Mayr, E. (eds) Genetics, Paleontology and Evolution (Princeton University Press. Paleontology and Evolution (Princeton Univ
1949; and Atheneum, New York, 1963)

3. Eldredge, N. \& Gould, S. J. in Models in Paleobiology (ed. Schopf, T. J.M.) 82-115 (Freeman, San Francisco, 1972).

4. Mayr, E. Animal Species and Evolution (Hanvard University Press, Cambridge, Massuchusetts, 1963)

5. Simpson, G. G. Tempo and Mode in Evolution (Columbia University Press, New York. 1944).

6. Levinton, J.S. Genetics, Paleontology, and Macroevolution (Cambridge University Press. New York, 1988).

7. Vrba, E. S. Science 221, 387-389 (1983)

8. Williams, G. C. Natural Selection: Domains, Levels, and Challenges (Oxford University Press, New York, 1992)

9. Fortey, R. A. Sci. Prog. Oxf. 72, 1-19 (1988). hypothesis ${ }^{5}$ of quantum evolution, but to speciation as a process of branching, characteristically occuring at geologically instantaneous rates - with trends then explained not as anagenetic accumulation, but as differential success by species sorting.

It has been remarked that new theories tend to go through three stages: dismissed first as false, then rejected as contrary to "religion" (read accepted ideas), and finally embraced as true but long known after all. How nice to be at that third stage already, when punctuated equilibrium has just become old enough to raise a glass legally to its own good health.

Stephen Jay Gould

Museum of Comparative Zoology,

Harvard University,

Cambridge, Massachusetts 02138, USA

Niles Eldredge

Department of Invertebrates,

American Museum of Natural History,

New York, New York 10024, USA

\title{
Longevity and testosterone
}

SIR - Nieschlag et al. ${ }^{1}$ concluded that testosterone may not be responsible for the difference in lifespan now present between men and women. But their data do not appear to me to support this statement.

With the standard deviations reported in ref. 1 the statistical analysis would not have the power to detect a difference in lifespan even of 5 years due to the small sample number. But anyhow there is a more important objection. The 'castrati' singers were almost exclusively from Italy $^{2}$, as were many famous singers in that period (this was the age of the Bel Canto $^{3}$ ). I therefore consulted an Italian life table. Because there are no accurate data for the seventeenth and the eighteenth century I examined a historical period in which the life expectancy was similar to that of the group under study for an individual who had reached the age of 30 .

In the year 1891 the expected age of death of an Italian man who had reached age 30 was 64.7 years and that of a woman 65.0 years ${ }^{4}$. The life expectancy in 1891 was indeed almost equal between Italian men and women at all ages. Even if the criteria with which I have selected this population are open to argument, it is clear that we cannot assume that there was a difference in mortality between the sexes at the time of the castrati.

It is only since the First World War that increased female longevity is clearly present in all the developed countries ${ }^{5}$. There are many examples of small or inverted differences in the less developed countries even today ${ }^{6}$ which cannot simply be explained by a high incidence of maternal death $^{5}$. The most important cause of the difference, when present, is an increase in men of premature death from heart disease $^{7}$. But in our 1891 Italian population, heart disease was listed as a cause of death only in $6 \%$ of the cases ${ }^{8}$.

In conclusion, we cannot yet absolve testosterone. This is important not only for understanding the smaller incidence of coronary heart disease among women, but also because androgen hormones are sometimes taken for non-medical reasons (for example, enhancement of athletic performance) and their potentially damaging effects should not be underestimated.

Giovanni Paternostro

Department of Biochemistry,

University of Oxford,

Oxford OX1 3QU, UK

1. Nieschlag, E., Nieschlag. S. \& Behre, H. M. Nature 366 215 (1993)

2. Sadie, S. (ed.) The New Grove Dictionary of Music and Musicians (Macmillan, London, 1992)

3. Scholes, P. A. (ed.) The Oxford Companion to Music 10th edn (Oxford University Press, 1970)

4. Preston, S. H. Keyfitz, N. \& Schoen, R. Causes of Death Life Tables for National Populations (Seminar Press, New York, 1972).

5. Stolnitz, G. J. Population Studies 10, No. 1, 17-42 (1956).

6. UN Statistical Yearbook 1990/91 38th issue (New York 1993).

7. Johansson, S. Cardiovasc. Clin. 19, 3-16 (1989).

8. Istituto Centrale di Statistica Sommario di Statistiche Storiche Italiane 1861-1955 (Roma, 1958).

\section{Scientific Correspondence}

Scientific Correspondence is intended to provide a forum in which readers may raise points of a scientific character. They need not arise out of anything published in Nature. In any case, priority will be given to letters of fewer than 500 words and five references. 